\title{
Obesity and the metabolic syndrome: the San Antonio Heart Study
}

\author{
Steven M. Haffner \\ Department of Medicine, The University of Texas Health Science Center at San Antonio, 7703 Floyd Curl Drive, \\ San Antonio, Texas 78229-3900, USA
}

\begin{abstract}
Obesity, especially visceral adiposity, is a major determinant of the development of type 2 diabetes. Both visceral adiposity and insulin resistance are strongly related to cardiovascular risk factors in diabetic and non-diabetic subjects. One of the areas where the correlation between visceral fat (upper body adiposity) and cardiovascular risk is most apparent is the prediabetic state. We have recently shown that only prediabetic subjects (those who later develop type 2 diabetes) who are insulin resistant and with upper body adiposity have increased triglycerides, decreased HDL cholesterol and high blood pressure.
\end{abstract}

Obesity: Metabolic syndrome: Type 2 diabetes: Prediabetic

\section{Introduction}

The concept of insulin-resistance syndrome (hypertension, dyslipidaemia, type 2 diabetes, insulin resistance and CHD) was initially developed by Professor Reaven (Reaven et al. 1993). The San Antonio Heart Study suggested that fasting insulin (a surrogate for insulin resistance) predicted the development of dyslipidaemia, hypertension and type 2 diabetes (Haffner et al. 1992; Table 1). Additionally, fasting insulin was significantly related prospectively to the number of metabolic disorders over 8 years (Haffner et al. 1992). However, in cross-sectional analysis from the Framingham Study (Meigs et al. 1997) the investigators found three factors for the metabolic syndrome, only one of which included insulin concentration. A number of reviews have discussed the insulin-resistance syndrome (Haffner \& Miettinen 1997; Liese et al. 1998); the latter review specifically talks about the interactions of insulin and obesity in the metabolic syndrome.

A number of investigators have suggested that visceral fat may comprise a key component of the insulin-resistance syndrome (Despres et al. 1991; Pouliot et al. 1994). Some data are available from the San Antonio Heart Study on the influence of visceral fat (or anthropometric surrogates of visceral fat such as waist-to-hip ratio) as predictors of components of the metabolic syndrome, especially hypertension and type 2 diabetes (Haffner et al. 1990; Wei et al. 1999). In the current review we examine these issues of obesity and visceral fat as predictors of the metabolic syndrome.

\section{Hypertension}

The San Antonio Heart Study is a population-based study in
Mexican Americans and non-Hispanic whites. The baseline examination was conducted in 1984-93, with a 7-year follow-up in 1991-94 (Haffner et al. 1990). In these analyses only non-diabetic, non-hypertensive subjects were included at baseline. Hypertension developed in 93 out of 1039 subjects. After adjustment for age, the BMI, waist-to-hip ratio, fasting glucose, triglyceride and fasting insulin predict the development of hypertension (Table 2; Haffner et al. 1990). Body mass index, fasting insulin and triglyceride levels predicted the development of hypertension in the Mexican Americans and non-Hispanic whites (Fig. 1). In addition, fasting insulin predicted the development of hypertension in both lean and obese subjects. In conclusion, a cluster of atherogenic changes may precede the development of hypertension, and both increased fasting insulin and overall adiposity predict the incidence of hypertension in important subgroups of patients.

Table 1. Eight-year incidence of metabolic disorders in subjects according to first and fourth quartile of fasting insulin at baseline

\begin{tabular}{|c|c|c|c|c|}
\hline \multirow[b]{2}{*}{ Disorder } & \multicolumn{2}{|c|}{$\begin{array}{l}\text { Baseline insulin } \\
\text { Quartile (\%) }\end{array}$} & \multirow[b]{2}{*}{ Relative risk } & \multirow[b]{2}{*}{$P$} \\
\hline & 1 & 4 & & \\
\hline Hypertension & 5.5 & 11.4 & 2.04 & 0.021 \\
\hline Hypertriglyceridaemia & $2 \cdot 6$ & 8.9 & 3.46 & $<0.001$ \\
\hline Low HDL-C & $16 \cdot 2$ & $26 \cdot 3$ & 1.63 & 0.012 \\
\hline High LDL-C & $16 \cdot 4$ & $20 \cdot 1$ & 1.23 & 0.223 \\
\hline Type 2 diabetes & $2 \cdot 2$ & 12.2 & 5.62 & $<0.001$ \\
\hline
\end{tabular}

HDL-C, high-density lipoprotein cholesterol; LDL-C, low-density lipoprotein cholesterol. Adapted from Haffner et al. (1992). 
Table 2. Anthropometric and clinical variables of non-diabetic normotensive subjects adjusted for age, gender and ethnicity by analysis of variance*

\begin{tabular}{|c|c|c|c|}
\hline \multirow[b]{2}{*}{ Baseline variables } & \multicolumn{3}{|c|}{ Conversion status at follow-up } \\
\hline & Hypertension & Normotension & $P$ \\
\hline Number of subjects $\dagger$ & 93 & 946 & - \\
\hline Mexican Americans (\%)† & 80 & 75 & 0.32 \\
\hline Male $(\%) \dagger$ & 28 & 42 & 0.007 \\
\hline Age, $y$ & $46(1.14)$ & $41(0 \cdot 35)$ & $<0.001$ \\
\hline Body mass index $\left(\mathrm{kg} / \mathrm{m}^{2}\right)$ & $31(0.55)$ & $28(0.17)$ & $<0.001$ \\
\hline Waist-to-hip ratio & $0.882(0.008)$ & $0.862(0.002)$ & 0.01 \\
\hline \multicolumn{4}{|l|}{ Triglycerides $\ddagger$} \\
\hline $\begin{array}{l}\mathrm{mmol} / \mathrm{l} \\
\mathrm{mg} / \mathrm{dl}\end{array}$ & $\begin{array}{c}1.62(1.45-1.79) \\
143(128-158)\end{array}$ & $\begin{array}{l}1.28(1.24-1.32) \\
113(110-117)\end{array}$ & $<0.001$ \\
\hline \multicolumn{4}{|l|}{ Glucose } \\
\hline $\begin{array}{l}\mathrm{mmol} / \mathrm{l} \\
\mathrm{mg} / \mathrm{dl}\end{array}$ & $\begin{array}{c}4.75(4.63-4.88) \\
85.6(83.4-87.9)\end{array}$ & $\begin{array}{c}4.71(4.67-4.75) \\
84.8(84.1-85.6)\end{array}$ & 0.05 \\
\hline \multicolumn{4}{|l|}{ Insulin (pmol/l)‡ } \\
\hline Fasting & $85.9(72.1-102.5)$ & $57.0(53.9-60.2)$ & $<0.001$ \\
\hline
\end{tabular}

*Values are given as mean $( \pm \mathrm{SE})$ or $(95 \% \mathrm{Cl})$ except where noted.

† Values are not adjusted for age, gender and ethnicity.

$¥$ Values are back-transformed from log transformation.

Adapted from Haffner et al. (1990).

\section{Incidence of diabetes}

The correlations for anthropometric variables at baseline in the San Antonio Heart Study are shown in Table 3 (Wei et al. 1999). A cohort of 721 Mexican Americans aged 25-64 years who were free of type 2 diabetes at baseline were followed for an average of $7 \cdot 2$ years; 105 new cases of type
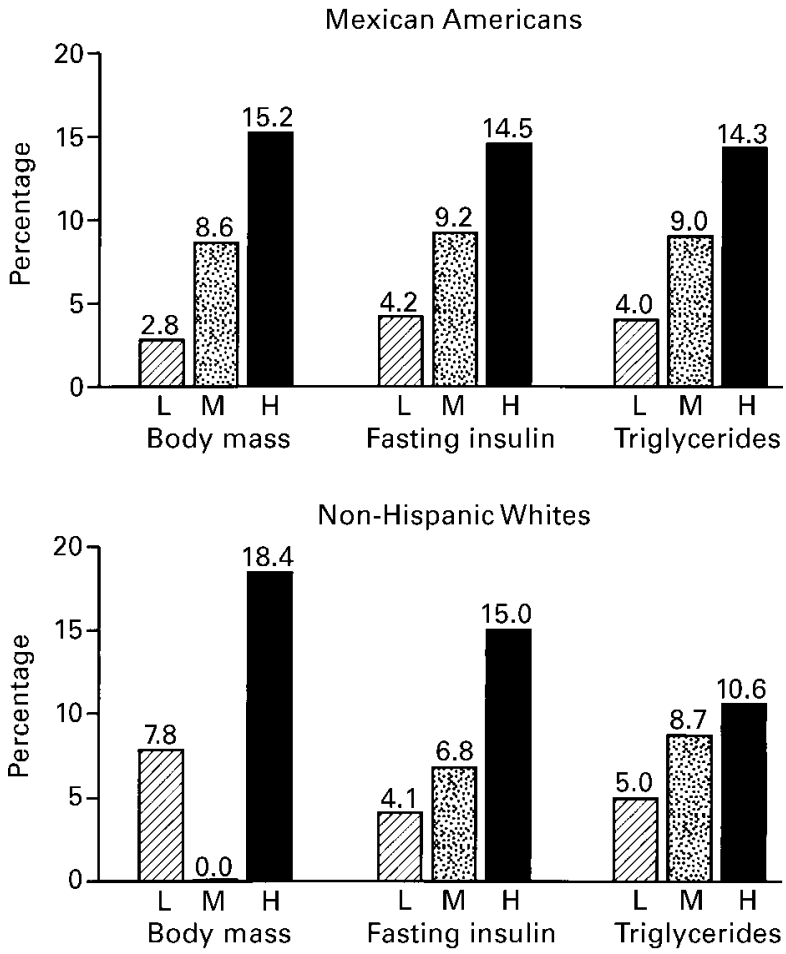

Fig. 1. Univariate relation of incidence of hypertension to BMl category (L, low, <25.2; M, medium, 25.2-29.6; H, high, $\geqslant 29.6$ ); insulin tertile (L, <44.4; M, 44.4-85.8; H, >85.8 pmol//); triglyceride tertile (L, $<1.03$ $\mathrm{mmol} / \mathrm{l}[<91 \mathrm{mg} / \mathrm{dl}] ; \mathrm{M}, 1.03-1.60$ [91-142]; $\mathrm{H},>1.60$ [ $>142]$ in Mexican Americans and non-Hispanic whites. The $P$ values were computed for test for trend. Adapted from Haffner et al. (1990).
2 diabetes were diagnosed. Body weight, BMI, waist circumference and waist-to-hip ratio (WHR) were all positively predictive of type 2 diabetes independent of age and sex (Table 4). Waist circumference was the strongest predictor of type 2 diabetes (Table 4 ). The predictive power of a single measurement of waist circumference was at least equal to that of WHR and BMI combined (Table 5). The risk of type 2 diabetes for those in the highest quartile of waist circumference was 11 times greater than for those in the lowest quartile $(95 \% \mathrm{CI}=4 \cdot 2-28 \cdot 8)$. The waist-type 2 diabetes relation was stronger in subjects with $\mathrm{BMI} \leqslant 27 \mathrm{~kg} / \mathrm{m}^{2}$ (adjusted odds ratio, $\mathrm{OR}=6.0$ for a $1 \mathrm{SD}$ difference) than in subjects with $\mathrm{BMI}>27 \mathrm{~kg} / \mathrm{m}^{2}(\mathrm{OR}=1.7$ for a $1 \mathrm{SD}$ difference). In multivariate analysis, waist circumference was the only significant predictor of type 2 diabetes in models that

Table 3. Spearman correlation analyses of selected anthropometric variables

\begin{tabular}{lccc}
\hline Variable & BMI & WHR & Waist \\
\hline Men & & & \\
WHR & 0.50 & - & 0.86 \\
Waist & 0.86 & 0.73 & - \\
Women & & & \\
WHR & 0.41 & - & 0.72 \\
Waist & 0.87 & 0.72 & - \\
\hline Adapted from Wei et al. (1999).
\end{tabular}

Table 4. The age-adjusted odds ratio for developing type 2 diabetes for a 1 SD difference at baseline in selected anthropometric variables according to gender

\begin{tabular}{lcccccc}
\hline \multirow{2}{*}{ Variable } & \multicolumn{3}{c}{ Women } & & \multicolumn{2}{c}{ Men } \\
\cline { 2 - 3 } \cline { 5 - 6 } & OR 95\% & $\mathrm{Cl}$ & & OR 95\% & $\mathrm{Cl}$ \\
\hline BMI $\left(\mathrm{SD}=5.7 \mathrm{~kg} / \mathrm{m}^{2}\right)$ & 1.51 & $1.21-1.90$ & & 1.69 & $1.07-2.65$ \\
Waist $(\mathrm{SD}=14.4 \mathrm{~cm})$ & 1.80 & $1.40-2.33$ & & 1.84 & $1.13-3.00$ \\
\hline
\end{tabular}

OR, adjusted odds ratio.

Adapted from Wei et al. (1999). 


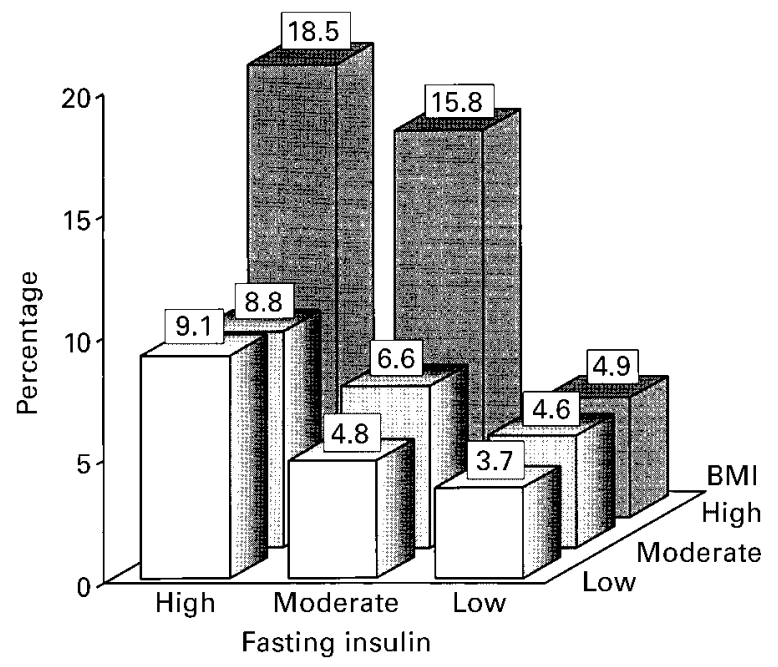

Fig. 2. Incidence of hypertension stratified by BMI. Values for BMI categories and insulin tertiles are explained in the legend to Fig. 1. Adapted from Haffner et al. (1990). included other anthropometric variables either separately or simultaneously (Table 6). The WHR and BMI were independent predictors of type 2 diabetes after adjustment for each other; however their predictive abilities disappeared after adjustment for waist circumference.

The data indicate that waist circumference is the best obesity-related predictor of type 2 diabetes. This finding suggests that the distribution of body fat, especially abdominal localization, is a more important determinant than the total amount of body fat in the development of type 2 diabetes in Mexican Americans. Similar data for nonHispanic whites were presented at the present symposium (unpublished results).

\section{Conclusions}

We have shown that obesity and adverse body-fat distribution predict the development of both hypertension and type 2 diabetes. For hypertension, BMI is the strongest predictor. Our data thus suggest different measures of overall body-fat distribution on overall adiposity, as associated with different

Table 5. Likelihood-ratio test for comparison of waist circumference, BMI and WHR as predictors of type 2 diabetes in logistic model ${ }^{*}$

\begin{tabular}{|c|c|c|c|c|}
\hline Model† & $\begin{array}{l}2 \times \ln \\
\text { likelihood }\end{array}$ & $\chi^{2}$ & d.f. & $P$ \\
\hline \multicolumn{5}{|l|}{ Model I for waist and BMI } \\
\hline Waist $(0.72)+$ BMI $(-0.13) \ddagger$ & $-540 \cdot 8$ & - & - & - \\
\hline Waist $(0.60)$ & $-541 \cdot 2$ & 0.4 & 1 & 0.53 \\
\hline BMI (0.44) & $-552 \cdot 6$ & $11 \cdot 8$ & 1 & 0.0006 \\
\hline \multicolumn{5}{|l|}{ Model II for waist and WHR } \\
\hline Waist $(0.49)+$ WHR $(0.21) \ddagger$ & -539.6 & - & - & - \\
\hline Waist $(0.60)$ & $-541 \cdot 2$ & $1 \cdot 6$ & 1 & 0.21 \\
\hline WHR (0.55) & $-552 \cdot 1$ & 12.5 & 1 & 0.0004 \\
\hline \multicolumn{5}{|l|}{ Model III for BMI and WHR } \\
\hline BMI (0.34) + WHR (0.42) & $-542 \cdot 7$ & - & - & - \\
\hline BMI (0.44) & -552.6 & 9.9 & 1 & 0.0017 \\
\hline WHR $(0.55)$ & $-552 \cdot 1$ & $9 \cdot 4$ & 1 & 0.0021 \\
\hline \multicolumn{5}{|l|}{ Model IV for waist, BMI, and WHR } \\
\hline Waist $(0.47)+$ BMI $(0.001) \ddagger+$ WHR $(0.21) \ddagger$ & -539.6 & - & - & - \\
\hline Waist $(0.60)$ & $-541 \cdot 2$ & 1.6 & 2 & 0.45 \\
\hline BMI (0.34)+WHR (0.42) & $-542 \cdot 7$ & $3 \cdot 1$ & 1 & 0.08 \\
\hline
\end{tabular}

${ }^{*} \beta$ presented for a 1 SD difference in the predictor variable at baseline. † All models include age and sex.

$\ddagger P>0.05$, otherwise $P<0.05$.

Adapted from Wei et al. (1999).

Table 6. Adjusted odds ratio (OR) of selected variables (1 SD difference) for type 2 diabetes in models with or without waist circumference

\begin{tabular}{|c|c|c|c|c|c|c|}
\hline \multirow{3}{*}{$\begin{array}{l}\text { Main variable } \\
\text { Waist }(\mathrm{cm}) \\
(\mathrm{SD}=14.4)\end{array}$} & & & \multicolumn{4}{|c|}{ Model 3} \\
\hline & \multicolumn{2}{|c|}{$\begin{array}{l}\text { Model } 1 \\
\text { Adjusted for age and sex } \\
\text { OR for main variable }\end{array}$} & \multicolumn{2}{|c|}{$\begin{array}{l}\text { Adjusted for age, } \\
\text { sex, and waist } \\
\text { OR for main variable }\end{array}$} & \multicolumn{2}{|c|}{$\begin{array}{c}\text { Adjusted for age, sex, } \\
\text { and main variables } \\
\text { OR for waist }\end{array}$} \\
\hline & 1.82 & $<0.0001^{*}$ & - & - & - & - \\
\hline $\begin{array}{l}\text { WHR } \\
(S D=0.091)\end{array}$ & 1.73 & $<0.0001$ & 1.23 & 0.200 & 1.63 & $<0.001$ \\
\hline $\begin{array}{l}\mathrm{BMI}\left(\mathrm{kg} / \mathrm{m}^{2}\right) \\
(\mathrm{SD}=5 \cdot 7)\end{array}$ & 1.51 & 0.0003 & 0.88 & 0.420 & 2.05 & $<0.001$ \\
\hline
\end{tabular}

${ }^{*} P$ value for odds ratio.

Adapted from Wei et al. (1999). 
metabolic outcomes. It will be important to explore whether these findings can be replicated in other populations. Most previous studies of clustering of cardiovascular risk factors have dealt with clustering of insulin resistance rather than obesity.

\section{References}

Despres JP, Prud'homme D, Pouliot MC, Tremblay A \& Bouchard C (1991) Estimation of deep abdominal adipose tissue accumulation from simple anthropometric measurements in men. American Journal of Clinical Nutrition 54, 471-477.

Haffner SM \& Miettinen H (1997) Insulin resistance implications for type II diabetes mellitus and coronary heart disease. American Journal of Medicine 103, 152-162.

Haffner SM, Miettenen H, Gaskill SP \& Stern MP (1990) Metabolic predictors of hypertension: the San Antonio Heart Study. Archives of Internal Medicine 156, 1994-2000.

Haffner SM, Valdez RA, Hazuda HP, Mitchell BD, Morales PA \& Stern MP (1992) Prospective analysis of the insulin-resistance syndrome (syndrome X). Diabetes 41, 715-722.
Liese AD, Mayer-Davis EJ \& Haffner SM (1998) Development of the multiple metabolic syndrome: an epidemiologic perspective. Epidemiologic Reviews 2, 157-172.

Meigs JB, D’Agostino RB Sr, Wilson PWF, Cupples LA, Nathan DM \& Singer DE (1997) Risk variable clustering in the insulin resistance syndrome: the Framingham Offspring Study. Diabetes 46, 1594-1600.

Pouliot M, Despres J, Lemieux S et al. (1994) Waist circumference and abdominal sagittal diameter: best simple anthropometric index of abdominal visceral adipose tissue accumulation and related cardiovascular risk in men and women. American Journal of Cardiology 73, 460-468.

Reaven GM, Chen Y-DI, Jeppesen J, Maheux P \& Krauss RM (1993) Insulin resistance and hyperinsulinemia in individuals with small, dense, low density lipoprotein particles. Journal of Clinical Investigations 92, 141-146.

Wei M, Gaskill SP, Haffner SM \& Stern MP (1999) Waist circumference as the best predictor of non-insulin dependent diabetes mellitus (NIDDM) compared to body mass index, waist/hip ratio and other anthropometric measurements in Mexican Americans. A 7-year predictive study. Obesity Research 5, 16-23. 